\title{
Social rank overrides environmental and community fluctuations in determining meat access by female chimpanzees in the Taï National Park, Côte d'Ivoire
}

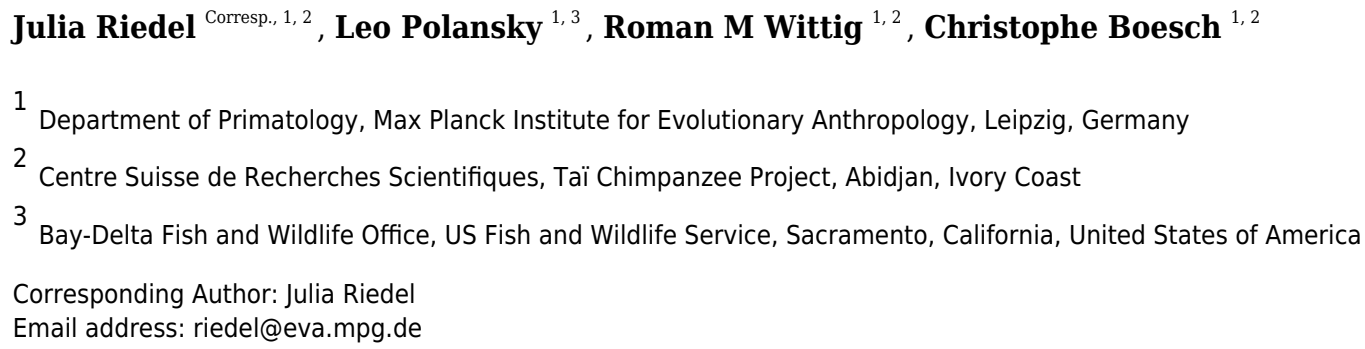

Meat, long hypothesized as an important food source in human evolution, is still a substantial component of the modern human diet, with some humans relying entirely on meat during certain times of the year. Understanding the socio-ecological context leading to the successful acquisition and consumption of meat by chimpanzees (Pan troglodytes), our closest living relative, can provide insight into the emergence of this trait because humans and chimpanzees are unusual among primates in that they both (i) hunt mammalian prey, (ii) share meat with community members, and (iii) form long-term relationships and complex social hierarchies within their communities. However, females in both human hunter-gatherer societies as well as chimpanzee groups rarely hunt, instead typically accessing meat via males that share meat with group members. In general, female chimpanzee dominance rank affects feeding competition, but so far, the effect of female dominance rank on meat access found different results within and across studied chimpanzee groups. Here we contribute to this debate on how female rank influences meat access while controlling for several socio-ecological variables. Multivariate analyses of 773 separate meat-eating events collected over more than 25 years from two chimpanzee communities located in the Taï National Park, Côte d'Ivoire, were used to test the importance of female dominance rank for being present at, and for acquiring meat, during meat-eating events. We found that high-ranking females were more likely to be present during a meat-eating event and, in addition, were more likely to eat meat compared to the subordinates. These findings about the importance of female social rank were robust to both large demographic changes (decrease of community size) and seasonal ecological changes (fruit abundance dynamics). In addition to social rank, we found that other female properties had a positive influence on presence to meat-eating events and access to meat given presence, including oestrus status, nursing of a small 
infant, and age. Similar to findings in other chimpanzee populations, our results suggest that females reliably acquire meat over their lifetime despite rarely being active hunters. The implication of this study supports the hypothesis that dominance rank is an important female chimpanzee property conferring benefits for the high-ranking females. 
2 Social rank overrides environmental and community fluctuations in determining meat access by female chimpanzees in the Taï National Park, Côte d'Ivoire

4

5 Julia Riedel 1,3, Leo Polansky 1,2, Roman M. Wittig 1,3 and Christophe Boesch 1,3

$9{ }^{1}$ Department of Primatology, Max Planck Institute for Evolutionary Anthropology, Deutscher

10 Platz 6, D-04103 Leipzig, Germany

$11{ }^{2}$ US Fish and Wildlife Service, Bay-Delta Fish and Wildlife Office, Sacramento, CA 95814, 12 USA

13 Taï Chimpanzee Project, Centre Suisse de Recherches Scientifiques, BP 1301, Abidjan 01,

14 Ivory Coast

15

16 Corresponding Author:

17 Julia Riedel

18 Department of Primatology, Max Planck Institute for Evolutionary Anthropology

19 Deutscher Platz 6, D-04103 Leipzig, Germany

20 E-mail address: riedel@eva.mpg.de 


\section{Abstract}

Meat, long hypothesized as an important food source in human evolution, is still a

24 substantial component of the modern human diet, with some humans relying entirely on meat

25 during certain times of the year. Understanding the socio-ecological context leading to the 26 successful acquisition and consumption of meat by chimpanzees (Pan troglodytes), our closest

27 living relative, can provide insight into the emergence of this trait because humans and 28 chimpanzees are unusual among primates in that they both (i) hunt mammalian prey, (ii) share 29 meat with community members, and (iii) form long-term relationships and complex social 30 hierarchies within their communities. However, females in both human hunter-gatherer societies 31 as well as chimpanzee groups rarely hunt, instead typically accessing meat via males that share 32 meat with group members. In general, female chimpanzee dominance rank affects feeding 33 competition, but so far, the effect of female dominance rank on meat access found different results 34 within and across studied chimpanzee groups.

35 Here we contribute to this debate on how female rank influences meat access while controlling for several socio-ecological variables. Multivariate analyses of 773 separate meat-

37 eating events collected over more than 25 years from two chimpanzee communities located in the Taï National Park, Côte d'Ivoire, were used to test the importance of female dominance rank for being present at, and for acquiring meat, during meat-eating events. We found that high-ranking females were more likely to be present during a meat-eating event and, in addition, were more

41 likely to eat meat compared to the subordinates. These findings about the importance of female 42 social rank were robust to both large demographic changes (decrease of community size) and 43 seasonal ecological changes (fruit abundance dynamics). 
on presence to meat-eating events and access to meat given presence, including oestrus status, nursing of a small infant, and age. Similar to findings in other chimpanzee populations, our results suggest that females reliably acquire meat over their lifetime despite rarely being active hunters. The implication of this study supports the hypothesis that dominance rank is an important female chimpanzee property conferring benefits for the high-ranking females.

\section{Introduction}

Hunting and meat eating are considered important behaviors shaping early hominid evolution and are proposed to be key innovations in the evolution of Australopithecines to Homo erectus (Isaac, 1978; Washburn, 1978; Leakey, 1981; Hill, 1982). In particular, meat consumption has for at least several decades been suggested as the food that powered brain expansion in human evolution (Washburn \& Lancaster, 1968; Milton, 1999). Meat has become a substantial component in many modern human diets, recently averaging $42 \mathrm{~kg}$ of meat per capita per year (Faostat, 2014).

Placed within the context of human evolution, observations of hunting and meat eating in our closest living relatives, chimpanzees (Pan troglodytes), are critical in helping to reconstruct early human behaviors (Wrangham, 1987; Boesch-Acherman \& Boesch, 1994; Gilby et al. 2017). Since early-published records of chimpanzee hunting and meat eating by Jane Goodall (1963), numerous other field studies have reported these as common chimpanzee behaviors (Boesch \& Boesch, 1989; Nishida, 1990; Uehara et al., 1992; Stanford, 1999; Mitani \& Watts, 1999; Boesch \& Boesch-Achermann, 2000). So although chimpanzee diets are composed primarily of fruits (Goodall, 1968; Sugiyama \& Koman, 1992; Morgan \& Sanz, 2006), meat is considered an 
67 of its high quality calorific package of protein, fat and micronutrients that are difficult to find in 68 plant foods (Stanford, 1999; Milton, 2003; Tennie et al., 2009).

The frequency of meat eating varies considerably across chimpanzees groups, sex and

70 individuals. In Taï National Park in Côte d'Ivoire (hereafter referred to as Taï), chimpanzee meat

71 eating varies with the seasons (wet/dry) and over the years, but is an important activity all year

72 round, taking up to $9 \%$ of their activity budget, with Taï males and females eating an average of

$73186 \mathrm{~g}$ and $25 \mathrm{~g}$ of meat per day, respectively (Boesch \& Boesch-Achermann, 2000). A stable

74 isotope study of hair and bones confirmed sex differences in meat consumption, with higher levels

75 of meat eating among Taï chimpanzee males compared to females (Fahy et al., 2013). For Gombe

76 chimpanzees (Tanzania), where similar to Taï regular hunting occurs, an average of $22 \mathrm{~g}$ of meat

77 per day is reported (Wrangham, 1975), with males eating an average of $55 \mathrm{~g}$ and females $7 \mathrm{~g}$

78 (Boesch \& Boesch-Achermann, 2000). At Ngogo (Uganda), the estimates for daily meat intake

79 are 41-55 $\mathrm{g}$ for males and $10 \mathrm{~g}$ for females. This big chimpanzees group hunts a lot with a total

80 annual biomass of $850 \mathrm{~kg}$ meat (Watts \& Mitani, 2002). Interestingly at Fongoli (Senegal), females

81 seem to hunt more compared to other study sites, here they account for $30 \%$ of all captures and

82 males for $70 \%$ (Pruetz et al., 2015). The female meat intake might be higher compared to the other

83 study sites. The Fongoli chimpanzees sometimes hunt with tools; females hunt more with tools

84 than males and prefer to hunt Galagos (Pruetz et al., 2015). There is a considerable variation in

85 the frequency of hunting and the amount of meat intake across the studied chimpanzee groups, but

86 in all groups, males hunt more than females and also eat more meat (Goodall, 1986; Stanford,

87 1999; Boesch \& Boesch-Achermann, 2000; Watts \& Mitani, 2002; Gilby et al. 2017).

88 Social rank can also play an important role in the access and consumption of meat

89 (O’Malley et al., 2016, but see Samuni et al., 2018b that found no effect of rank on meat access). 
90 A study of Gombe Kasekela chimpanzees showed that females use their dominance rank position

91 to maximize their access to meat, with high-ranking females consuming more meat than

92 subordinates (O’Malley et al., 2016). Further, it has been shown that meat is an important food

93 source for female chimpanzees during periods of pregnancy and nursing (O’Malley et al., 2016),

94 a nutritionally and energetically costly body state for females (Clutton-Brock \& Harvey, 1978;

95 Emery Thompson et al., 2012). The Gombe study found an interaction between reproductive state

96 and rank, and revealed that high-ranking females do not differ in meat consumption between

97 different reproductive states, but low-ranking females do, with low-ranking females consuming

98 more meat during pregnancy than during lactation and baseline (not pregnant/ not lactating

99 females) (O’Malley et al., 2016). In the Gombe Kasekela group, high-ranking females have a

100 higher hunting probability compared to lower ranking females, but this was not true at the Gombe

101 Mitumba group and Kanyawara group in Kibale, Uganda (Gilby et al., 2017). In Sonso

102 chimpanzees of the Budongo forest in Uganda, high-ranking individuals monopolize meat

103 irrespective of their own hunting role, whereas in the neighbouring Waibira community no rank

104 effect on meat access was found (Hobaiter et al., 2017). Dominance rank has been shown to affect

105 sociality, ranging, and feeding competition in female chimpanzees at Gombe (Pusey et al., 1997;

106 2005; Williams et al., 2002a;b; Murray et al., 2006; 2007) and Kibale (Emery Thompson et al.,

107 2007; 2010; Kahlenberg et al., 2008).

108 As chimpanzees live in fission-fusion societies whereby individuals form smaller foraging

109 parties when food abundance is low (Boesch \& Boesch-Achermann, 2000; Goodall, 1986; Mitani

110 et al., 2002), it is important to consider their gregariousness when studying how they access meat.

111 The flexibility provided by fission-fusion grouping helps reducing within-group contest

112 competition over food, and chimpanzee females tend to be less social then males, but differences 
113 between study sites have been documented (Boesch \& Boesch-Achermann, 2000; Fawcett, 2000;

114 Wakefield, 2002; Williams et al, 2002b; Lehmann \& Boesch, 2008). Taï females are more

115 gregarious compared to those from Kibale and Gombe (Wrangham \& Smuts, 1980; Goodall, 1986;

116 Wrangham et al., 1992; Pusey et al., 1997; Williams et al., 2002b, Lehmann \& Boesch, 2008).

117 Furthermore, it has been shown that high-ranking females are more gregarious with other females

118 than are low-ranking females in Gombe (Williams et al., 2002b). At Taï, a high rank appears to

119 allow females to be more gregarious in times of low fruit abundance, whereas during seasons of

120 high fruit abundance, all females were highly gregarious, regardless of their rank (Riedel et al.,

121 2011). When fruits were scarce, low-ranking females decreased their gregariousness, whereas

122 high-ranking females' social behaviour changed little, revealing the social benefits of a high rank

123 position (Riedel et al., 2011).

124 Taï males are primarily the hunters; they capture the prey in most cases, and subsequently

125 share it with their community members (Boesch \& Boesch-Achermann, 2000; Samuni et al.,

126 2018b). Taï females participate in hunts much less than males, with their involvement in hunting

127 being approximately 13\%-15\% (Boesch \& Boesch, 1989). That chimpanzee females can also be

128 successful hunters has been shown from Fongoli, where about $40 \%$ of all successful hunters were

129 females and the two high-ranking adult females were among the top 10 hunters (Pruetz et al.,

130 2015). Because hunting participation can largely determine meat access (Boesch \& Boesch-

131 Achermann, 2000; Samuni et al., 2018b), the consumption of meat is not evenly distributed

132 between community members, resulting in some individuals frequently not receiving meat while

133 others obtain it regularly (Boesch \& Boesch, 1989; Boesch, 1994; Watts \& Mitani, 2002; Boesch

134 \& Boesch-Achermann, 2000). 
In the absence of hunting participation, "cheating", defined as consuming meat from a

136 successful hunt that an individual did not participate in, can occur. By cheating, females are able

137 to increase their caloric intake without suffering the energetic costs related to hunting. Females are

138 more successful at cheating than males because male hunters tolerate female cheaters much more

139 than male cheaters (Boesch \& Boesch-Achermann, 2000).

140 In Taï, male hunters share meat unevenly with females, and males might share with

141 cheating females because females copulated more with males who shared meat with them than

142 with males who did not share meat with them, irrespective of e.g. male rank, female rank, or age

143 (Gomes \& Boesch, 2009). In contrast, three other chimpanzee study sites did not find support for

144 the meat-for-sex hypothesis: at Ngogo, Gombe and Kanyawara the males did not gain mating

145 advantages through meat sharing (Mitani \& Watts, 2001; Gilby, 2006; Gilby et al., 2010).

146 Despite the low frequency in which females participate in hunting, some high-ranking

147 females in the Taï North group can reach a very high status in the meat access order although they

148 did not participate in the hunt, occasionally even surpassing low and middle ranking males (Boesch

$149 \&$ Boesch-Achermann, 2000). In the Taï North group, high-ranking females monopolize and

150 possess the food after a dyadic female/female food conflict and meat was the main reason for

151 contests over monopolizable food among Taï females (Wittig \& Boesch, 2003). Recent results

152 investigating all food sharing events in Taï South and East groups found a three-way interaction

153 between rank of the beggar and the possessor with sex on food access through sharing (Samuni et

154 al., 2018a), indicating that rank neighbours were sharing more than dyads with a larger rank

155 asymmetry. When investigating access to meat only, however, another study on the same

156 chimpanzee groups found an impact of hunt participation, age, prey size and fruit availability on

157 meat consumption, but none by sex or dominance rank (Samuni et al., 2018b). 
159 of different social factors on female success to access meat. The central two hypotheses tested here

160 are that in comparison to lower ranking females, high-ranking females are more likely to (1) be

161 present during a meat eating event, and to (2) have increased access to meat given both are at a

162 meat eating event. The primary predictor variable of interest here is female dominance rank, while

163 controlling for age, oestrous status and the nursing of a small infant, important factors in

164 determining feeding competition more broadly (Riedel et al., 2011; O’Malley et al., 2016) and

165 hence important control variables to include when testing for the importance of rank. We added

166 socio-ecological control variables such as community size and fruit abundance to test for the

167 robustness of rank effects besides seasonal ecological changes and large demographic changes

168 (decrease of community size).

169

170 Materials \& Methods

171 Study site and data collection

172 We analysed meat-eating data from two habituated chimpanzee communities in Taï,

173 labelled North and South due to the relative geographic locations of their territories. Habituation

174 of the North and South groups started in 1979 and 1989, respectively. Researchers and local field

175 assistants have since continuously observed both communities. During the study period, the North

176 group decreased from 76 to 19 individuals and the South group from 56 to 39 chimpanzees (Figure

177 1), largely related to disease outbreaks, poaching and not to food availability.

178 Human observers carried out daily focal animal follows (Altmann, 1974) using

179 standardised check-sheets and shifted to ad libitum data recording for hunting and meat eating

180 events. Inter-observer reliability among Taï assistants is very good (Deschner et al., 2004; Riedel 
181 et al., 2011). During the daily focal animal follows, the observers make continuous records of

182 social interactions, party composition, and number and identity of females in oestrous encountered

183 by the focal chimpanzee throughout the observation day. From these focal data, we were able to

184 identify female dominance rank and the oestrous status. At hunting and meat eating events, the

185 assistants changed the focus from the focal animal to the whole hunting and meat-eating situation

186 and recorded as much information as possible about all visible individuals and interactions

187 between them. At meat eating events, observers noted which chimpanzees were present, who held

188 the prey, dyadic membership in meat sharing events, who was begging, who ate meat, who was

189 aggressive and received aggression, as well as consumption time and prey details such as species

190 and age-class. From the ad libitum data, we obtained information on whether a female was present

191 or not within the meat-eating party, and whether the female got and ate meat or not. This includes

192 all data whenever a female was eating meat, independently if she received the meat in whatever

193 way, through sharing, begging or stealing, or when she had captured herself a prey. We were not

194 able to include the amount of meat eaten by the female, because sadly the collected data was not

195 such detailed.

196 The dataset covers a 27-year period for the North group (1987 - 2014) with 451 meat-eating

197 events, and a 15-year period for the South group (1999 - 2014) with 376 meat-eating events. Due

198 to logistical constraints, not all meat-eating events during this period were recorded. Our meat

199 eating analyses focused on adult females, defined to be 13 years or more (Boesch \& Boesch-

200 Achermann, 2000), with 39 adult females from the North group and 33 females from the South

201 group. Females in Taï give birth to their first infant when they are approximately 13 years old, at

202 this age they are also fully grown and defined to be adult (Boesch \& Boesch-Achermann, 2000). 
From the 827 observed meat-eating events, 773 had at least one adult female present and

204 these were used for analysis. Analysis of data for which at least one female from each rank category

was present $(\mathrm{N}=464)$ did not differ from the results using the full dataset; thus we present results

based on the entire 773 events dataset. The meat eating events were almost entirely on separate

289) for North group.

Assistants trained in botanical monitoring censused fruit tree phenology every month using established routes in both chimpanzee territories. They noted the presence of ripe fruits of tree

211 species whose fruits were chimpanzee foods (Anderson et al., 2002; 2005; Polansky \& Boesch, 212 2013).

All field protocols, data collection procedures, and data analyses were conducted in

214 accordance with wildlife research protocols and ethical standards of the Max Planck Society in

215 Germany, "Ministère de l'Enseignement supérieur et de la Recherche scientifique", "Ministère des 216 Eaux et Forêts", and "Office Ivoirien des Parcs et Réserves" in Côte d'Ivoire.

Data analysis, model predictors and motivations

We constructed two models for the response variables of (i) whether a female was present or absent in the meat eating party (hypothesis 1) and (ii) whether the female did or did not receive meat (hypothesis 2). Both models therefore have a bivariate response variable. We considered four 222 'individual female' properties and 'socio-ecological' properties as predictor variables, with 223 interactions between some of these predictors, which we describe next.

\section{Dominance rank}


According to Wittig and Boesch (2003), we expected linear dominance hierarchies for the

226

227

228

229

230

231

232

233

234

235

236

237

238

239

240

241

242

243

244

245

246

247

adult females in Taï. Using the software package MatMan (De Vries 1995), we determined annual

linear dominance hierarchies following the direction of greeting behaviour: pant-grunts (PG), greeting-hoohs (GH) and greeting-pants (GP) (Wittig \& Boesch, 2003). Only 6 out of 44 annual dominance hierarchies were significantly linear. The reasons why we rarely detected linear female hierarchies are a high percentage of unknown dyadic dominance relationships between females and years with just four adult females in the North group. Due to this, we implemented three rank categories (high, middle and low) following the method used in Gombe by Pusey and colleagues (1997). We determined rank categories as follows. High-ranking females either gave no greetings to any females or gave occasional greetings to other high-ranking females and received greetings from middle- and low-ranking females. Middle-ranking females greet to high- and some middleranking females, and received greetings from low- and some middle-ranking females. Lowranking females rarely, if ever, received greetings from any adult females but often gave them to middle- and high-ranking females. When there was no greeting behavior observed between a female dyad in a certain year, we considered the ranks and interactions between these females in the year before and after. Furthermore, we consulted other rank data published about the Taï females (Boesch \& Boesch-Achermann, 2000; Wittig \& Boesch, 2003) and have always been able to assign females to one of the three categories. Female rank categories remained stable across years in both communities, with 58 of 80 females maintaining a single rank category over the study period. Twenty-two females moved to the adjacent category, mostly from low to middle (10 females) and from middle to high (10 females). Only two females (one in each community) dropped in rank from high to middle during the last years before death, as their physical condition deteriorated. A recent study from Taï also found that female dominance hierarchies of both the 
248 North and South group were largely stable over time and only few rank changes were described

249 (Mielke et al., in press).

250 Nursing a small infant

251 We controlled whether the female was nursing a small infant ( $\leq 2$ years old) on the day of

252 the meat-eating event because several studies have shown that chimpanzee mothers are less 253 gregarious (Goodall, 1986; Takahata, 1990; Sakura, 1994; Wrangham, 2000; Williams et al., 254 2002b; Otali \& Gilchrist, 2006; Murray et al., 2007; but also see Riedel et al., 2011). Mothers with 255 small infants might avoid meat-eating events for the protection of their infants because of the large 256 party sizes and competitive interactions to access meat at these events (Boesch \& Boesch257 Achermann, 2000). Alternatively, nursing females may disproportionately benefit from the 258 nutritive value of meat, so it is also plausible to predict that they would try to join meat-eating 259 events at higher frequencies. Males might prefer to share meat with mothers and their infants 260 (potentially their own offspring) as a provisioning strategy. In Gombe chimpanzees, the 261 reproductive state of females influenced meat consumption, with pregnant females consuming 262 more meat than lactating and not pregnant/ not lactating females (O'Malley et al., 2016). 263 Furthermore, it has been shown in Gombe and Kanyawara that females with a small infant do not 264 avoid hunting; females were equally likely to hunt red colobus whether or not they had an offspring 265 under two years of age (Gilby et al., 2017).

266 Oestrous status

267 We controlled for oestrous state as females with a maximal sexual swelling are more 268 gregarious (Boesch \& Boesch-Achermann, 2000) and adult males tend to share more meat with 269 oestrous than with anoestrous females in Taï given their proportional representation in hunting 270 parties (Gomes \& Boesch, 2009). The same result has been found in Ngogo (Mitani \& Watts, 
271 2001: but see Gilby, 2006 and Gilby et al., 2010 for no effect in Gombe and Kanyawara).

272 Assistants recorded the oestrous status, which coded sexual skin swellings after visual inspection

273 following Furuichi (1987). Three stages of tumescence were coded: (1) no swelling: minimal size

274 and maximal degree of wrinkling; (2) partial swelling: relative increase/decrease in size and

275 loss/appearance of wrinkles compared with stage 1 or 3; (3) maximum swelling: maximum size

276 with no wrinkles and tight appearance. For the analysis we used whether the female had a maximal

277 swelling at the meat-eating event.

278 Age

279 We controlled for the age of the adult female although Wittig and Boesch (2003) found

280 that female linear hierarchy in Taï was related to the outcome of the contest, while it was

281 independent of age. Other studies in Gombe and Mahale found that females increased their rank

282 as they aged (Nishida, 1989; Pusey et al., 1997). Older Taï chimpanzees gained more access to 283 meat (Samuni et al., 2018b).

284 Number of females and males

285 We controlled for the number of adult females and males present at the meat-eating event 286 because an increase in competitors also increases the within-group contest competition over food 287 (Wittig \& Boesch, 2003), although sub-group size previously had no effect on meat consumption 288 in Taï East and South group (Samuni et al., 2018b).

289 Community ID

290 We controlled for potential differences across the two chimpanzee communities (Luncz et 291 al., 2012) and included to which community the female belonged (either North or South group).

292 Community size 
294 communities hunting frequency increases as well as the number of hunters acting together (Mitani

295 \& Watts, 1999; Boesch \& Boesch-Achermann, 2000; Watts \& Mitani, 2002). Both affect the

296 amount of meat available within one community. Since over the study period, the community sizes

297 of both communities decreased dramatically (Figure 1), and for South group later increased again,

298 we included into our analysis monthly community size to test for the potential demographic effect

299 that could importantly affect the role of dominance on securing food and female meat access.

300 Community size for each of the two communities was recorded at monthly intervals and the size

301 recorded closest to the meat-eating event was used.

302

303

304

305

306

307

308

309

310

311

312

313 314 (1998).

315

316

317

\section{Insert Figure 1 here}

\section{$\underline{\text { Fruit abundance index }}$}

Chimpanzee hunting behavior and meat eating frequency in Taï is seasonal and peaks in September / October each year (Boesch \& Boesch-Achermann, 2000) at the beginning of a major peak in the monthly fruit abundance index (FAI) (Figure 2; see also Polansky \& Boesch, 2013). In contrast, a recent study on the Taï chimpanzees found that meat accessibility increased with a decrease in fruit availability (Samuni et al., 2018b). Therefore, we considered a monthly fruit abundance index (FAI) as an ecological predictor variable for female presence at meat-eating events and meat access. To obtain a monthly FAI we used the monthly percentage of observed trees presenting ripe fruits eaten by the Taï chimpanzees following Wrangham and colleagues

$-$


318 Interactions between some predictors

319 Cultural differences between the North and South groups have been described (Luncz et

320 al., 2012), so we included an interaction of female dominance rank and community ID into both

321 models. Because intra-annual dynamics of FAI are substantial (Anderson et al., 2005, Polansky \&

322 Boesch, 2013), we included an interaction between FAI and female dominance rank into both

323 models. We included the interaction of number of females with rank into both models. Female

324 dominance rank might have less of an influence for presence at meat eating events if the number

325 of adult females is low and therefore there is less competition. The same might be true for the

326 access to meat, when there are many other female competitors at the meat-eating event, high rank

327 might have a strong influence on the chances of accessing meat. Whereas when there is only a

328 small number of other females present all of them independently of their rank might receive parts

329 of the males share.

330 In addition, we included the interaction between female dominance rank and oestrous status

331 into both models, because females in oestrous are very social and interesting for the males in Taï

332 (Deschner et al., 2004), and independent of their rank they might be present and access meat. So

333 not only high-ranking females in oestrus might get meat, but also low ranking females in oestrus.

335 Statistical Analyses

336 Generalized linear mixed models (GLMM) with a logit link function were built to analyze

337 the significance of the factors described above. The GLMM framework accommodates the

338 bivariate data (indicating either female presence or absence or whether or not she received meat,

339 given presence at a meat eating event), while the mixed structure (both fixed and random effects)

340 allows proper treatment of repeated measurements on individual females and meat eating events 
341 due to unobserved variables (e.g. total amount of meat available). Fixed effect predictor variables

342 were adult female dominance rank, age, oestrous status, whether the individual was nursing an

343 infant, community ID, FAI, the number of adult males present, and number of adult females

344 present (community size was highly correlated with number of adult females in the presence

345 model). Random effects grouping variables were the individual female ID and the meat-eating

346 event ID. As discussed previously, for both models we included the interactions of dominance

347 rank and FAI, dominance rank and community ID, dominance rank and number of adult females

348 present, and dominance rank and oestrus status.

349 We fit models in the R version 3.5.2 environment (R Development Core Team, 2018) using

350 the lme4 package (Bates et al., 2015) and followed the general guidelines described by Bolker and

351 colleges (2009). The general model building process proceeded by first fitting a model with only

352 random effects to ensure estimated standard deviations were not close to zero. For the presence

353 model, this revealed numerical issues when random slopes were allowed for categorical predictor

354 variables (oestrus, nursing an infant, and dominance rank), so these were removed prior to

355 estimating a null model with only an intercept and supported random effects. For the meat access

356 model, no random slopes were included to avoid numerical issues. Given the null model consisting

357 only of an intercept, random effects, and an overall variance estimate, the full model including

358 main effects and interactions along with random effects was compared to the null model using a

359 likelihood ratio test (LRT). Interaction terms were removed one at a time from the full model and

360 their statistical support quantified using LRTs. Because the interactions were not statistically

361 supported, reduced models that excluded all interaction terms was re-fit to facilitate direct

362 interpretation of the coefficient estimates, and the support for each of these main effects was

363 evaluated using LRTs by removing each predictor variable one at a time. 

mean $=0$ and standard deviation $=1$ to increase model fitting stability. Furthermore, multicollinearity was checked by examining the generalized variance inflation factors (GVIF; Zuur

367 et al., 2009) as implemented in the car package (Fox \& Weisberg, 2011) in a full model without 368 interactions or random effects. This indicated that community size and number of females were too correlated $(\mathrm{GVIF}=21.094)$ to simultaneously include in the presence model. For both models, residual correlations within individual were investigated in two ways using functions available in the stats package of $\mathrm{R}$ ( $\mathrm{R}$ Development Core Team, 2018): i) to make sure there was no autocorrelation using the acf function, and ii) to see if there was a trend as a function of the number of days since the last time the individual was included in the analysis using the $1 \mathrm{~m}$ function. In each case, there was no evidence of problematic residual patterns. We remark that there was no strong evidence (GVIF values always less than 2) that female age and dominance rank were 376 correlated.

\section{Results}

Seventy-two different adult females were observed, two of which never were present at any meat-eating event. Of the 773 events, at least one low, middle, and high-ranking adult female 381 attended $530(69 \%), 677(88 \%)$, and $697(90 \%)$ events. The number of events at least one female 382 of a given rank received meat given that rank class was present was $329(62 \%), 556(82 \%)$, and 383 619 (89\%) for low, middle and high rank class, respectively. 

events was significantly better than a null model with only random effects and an overall intercept (test statistic $234.331, \mathrm{df}=17, \mathrm{P}$-value $<0.001$ ). All proposed interactions were not significant

389 (Table 1). The reduced model refit without including these interactions was also significantly 390 better than the null model (test statistic 224.385, $\mathrm{df}=9$, $\mathrm{P}$-value $<0.001$ ) but not worse than the full 391 model (test statistic 9.946, $\mathrm{df}=8, \mathrm{P}$-value $=0.269$ ). Parameter values and individual term significance of the reduced model are shown in Table 1. This indicates that female dominance rank, nursing a small infant, oestrus status, and the increased fruit abundance (FAI) have significant positive influence on the probability of females being present at a meat eating event. Increased number of males' present at the meat-eating event resulted in a decrease in the probability of females being present. Not significant was age, number of females, and community ID.

398

399 400

401

402 403 404 405 406 407 408

Probability of females accessing meat given presence at a meat-eating event The full model (including interactions) for the probability of accessing meat given presence at a meat eating event was significantly better than a null model with only random effects and an overall intercept (test statistic 166.142, $\mathrm{df}=18, \mathrm{P}$-value $<0.001$ ). All proposed interactions were not significant (Table 2). The reduced model refit without including these interactions was also significantly better than the null model (test statistic 158.007, $\mathrm{df}=10, \mathrm{P}$-value $<0.001$ ), but not worse than the full model (test statistic $8.135, \mathrm{df}=8, \mathrm{P}$-value $=0.420$ ). 
2. This indicates that female dominance rank, age, nursing a small infant, and oestrus status have

411 significant positive influence on the probability of females accessing meat, while increased

412 community size and increased number of females statistically decreased the likelihood to obtain

413 meat. The number of males, FAI, and community ID were not significant.

414

415

416

417

418

419

420

421

422

\section{Insert Table 2 here}

\section{Discussion}

We found support for our two principal hypotheses, that high-ranking females were more likely to be present during a meat-eating event and when present they were more likely to eat meat compared to the subordinates. This research contributes to a growing body of literature on the topic, where high female rank has also been shown to provide priority of access to high quality foods in Kibale and Gombe chimpanzees (Murray et al., 2006; 2007; Kahlenberg et al., 2008; Williams et al., 2002a).

For chimpanzees at Taï, our analyses further indicated that this positive effect of female dominance rank on acquiring meat was stable for the two chimpanzee communities (North and South) over a long period (more than 25 years). During this time, both communities experienced large declines in size with associated demographic changes that include different numbers of adult females and adult males, individual identities, relationships and friendships lost from one day to the next and important changes in the communities' dominance hierarchies. In addition, the intraannual fruit food fluctuations in Taï are quite strong and have been increasing in the past decade (Anderson et al., 2005, Polansky \& Boesch, 2013). Despite these changes in demographic and 
433 environmental conditions, no interactions between female social rank and the different socio-

434 ecological variables was detected; the rank related behaviors of these female chimpanzees are both

435 stable and robust across the two communities. Further, the rank contribution to meat access

436 remained constant across all these social changes.

437 In humans, sharing of food has been proposed to be the result of a collective action problem

438 due to living in a risky foraging niche that produces a set of social norms of production and sharing

439 (Jaeggi \& Gurven, 2013). In other words, humans live in a niche were food sharing became a

440 necessity. Considering that meat brings along a number of important micronutrients (Milton, 2003;

441 Tennie et al., 2009), it seems that meat, acquired through the presence of sharing, is an important

442 component of the diet in Taï chimpanzees.

443 Two recent studies in Taï, over a shorter period of time, focusing on dyadic interactions or

444 detailed hunting characteristics, have shown that social rank independent of sex has only a limited

445 effect in the food sharing behaviour of the Taï chimpanzees or their ability to access meat after a

446 hunt (Samuni et al., 2018a;b). In contrast, focusing on the characteristics of the females, here we

447 found a clear effect of rank on meat access by females, with dominant females accessing more

448 often meat than subordinates. At least three reasons may account for this difference: (1) since we

449 used data over 25 years the analysis had to fit the available long-term data, preventing us from

450 analysing for example the effects of hunt participation or reciprocal relationships on meat access;

451 (2) our research question was different and we did not include dyadic relationships; and (3) due to

452 missing dyadic dominance relationships, we used three rank categories, which may provide a

453 slightly different picture compared to linear dominance hierarchies.

454 Our finding that female dominance rank affects accessibility of valuable resources is

455 consistent with findings that high rank confers advantages during contest competition over food 
456 (Wittig \& Boesch, 2003). In Taï female contests over food, being dominant over a competitor

457 provided an advantage, as dominant conflict partners possessed the food significantly more

458 frequently after conflicts than did subordinates independent from the initiator (Wittig \& Boesch

459 2003). Therefore, our research points to the importance of rank for acquiring meat, the causative

460 mechanisms by which rank confers these benefits remain to be studied. Research on food sharing

461 in Taï has shown that mutual grooming relationships predict best with whom to share food (Samuni

462 et al., 2018a). Therefore, it could be that dominant females are more successful in building and

463 maintaining social relationships with males. In contrast, studies in Gombe have shown that

464 harassment predicts best the outcome of meat sharing (Gilby 2006). Therefore, an alternative

465 hypothesis would be that dominant females could be better in harassing males than subordinates,

466 although harassment has not been shown to be a strong predictor of food sharing in Taï (Samuni

467 et al., 2018a). Finally, in Taï dominant females invest more in sons (Boesch 1997) and therefore

468 sons might share more meat with their mothers, making kin relationships a main predictor for meat

469 sharing. Other important variables to be investigated further could include begging, stealing,

470 female hunting, dyadic associations, kinship and grooming (Gilby, 2006; Gilby et al., 2010;

471 Samuni et al., 2018a;b).

472 In Gombe and Kibale, high ranking females occupied higher-quality areas while 473 subordinates had to settle elsewhere (Murray et al., 2006; 2007; Kahlenberg et al., 2008; Williams

474 et al., 2002a) resulting in higher reproductive success for dominant females (Pusey et al., 1997;

475 2005; Emery Thompson et al., 2007). A better-fed female can invest more energy in reproduction

476 and thereby produce more offspring, or she can supply more food to her offspring. In Gombe, the

477 five most successful females at getting large amounts of meat had more surviving offspring than

478 did the five least successful females (Mc Grew, 1992). 

populations besides differences in demography and female sociality (Wrangham, 2000; Fawcett, 2000; Boesch \& Boesch-Achermann, 2000; Williams et al., 2002a;b; Lehmann \& Boesch, 2008).

482 Taï females are more gregarious compared to those from Kibale and Gombe where females were 483 relatively asocial (Wrangham \& Smuts, 1980; Goodall, 1986; Wrangham et al., 1992; Pusey et al., 1997; Williams et al., 2002b). Females in Kibale and Gombe seem to disperse and to be less gregarious to reduce within-group contest competition. The higher gregariousness in Taï females may result from a combination of higher fruit abundance (Boesch, 2009) and higher predation pressure at Taï (Boesch, 1991; 2009) compared to the other study populations. Unequal access to monopolizable food, such as meat, might be an explanation for the development of the linear hierarchy in Taï females (Wittig \& Boesch, 2003), which we were only able to find in some of the years we studied. Female dominance rank might help to reduce direct dyadic fighting by giving access to the dominant individual before even a conflict or fight have to evolve. which we confirmed. It remains unclear why older chimpanzees are more likely to access meat. It may be due to better begging and/or hunting skills. One hypothesis is that older females can have stronger friendships with chimpanzees in their community and can rely on long-term cooperative exchanges that gives them access to shared foods such as meat (Samuni et al. 2018a). In addition, older females are also preferred mating partners by male chimpanzees (Muller et al. 2006). oestrous status of the female. We found that oestrous females in Taï were more likely to be present and to get meat than females with no oestrous. This agrees with the findings that oestrous females were more gregarious than anoestrous ones (Boesch \& Boesch-Achermann, 2000), and that adult 
502 males share more meat with oestrous than with anoestrous females, when controlled for their

503 proportional representation in hunting parties (Gomes \& Boesch, 2009).

504 Our results show that a nursing female with a small infant in Taï did not avoid meat eating

505 events where elevated levels of intra-group aggression can occur. The increased need for high

506 value food such as meat to support nursing an infant is a likely factor motivating these females to

507 acquire meat. This goes in line with the findings from Gombe and Kanyawara were females with

508 a small infant did not avoid hunting (Gilby et al., 2017). Chimpanzee mothers in Taï remained as

509 gregarious as non-mothers (Riedel et al., 2011), in contrast to other study populations, where

510 mothers are less gregarious than non-mothers (Goodall, 1986; Murray et al., 2007; Williams et al.,

511 2002b; Takahata, 1990; Sakura, 1994; Wrangham, 2000; Otali \& Gilchrist, 2006). Our results

512 about lactating females accessing meat better than non-lactating females, confirms the findings

513 from Gombe, where pregnant females consumed more meat than lactating and not pregnant/not

514 lactating females (O’Malley et al., 2016). An interaction between reproductive state and rank in

515 Gombe females, revealed that high-ranking females do not differ in meat consumption between

516 different reproductive states, but low-ranking females do, with low-ranking females consuming

517 more meat during pregnancy than during lactation and not pregnant/ not lactating females

518 (O’Malley et al., 2016).

519 For the ecological variable that we studied, we found that fruit abundance had no 520 significant effect on female meat access, but plays a role on female presence at meat eating events,

521 with more females being present during times of high fruit abundance. That those periods of high

522 fruit abundance result in higher party sizes and sociality in Taï chimpanzees has been shown before

523 (Doran, 1997; Riedel et al., 2011). 
In Taï, females hunt much less than males, involvement in hunting was only $13 \%-15 \%$

525 (Boesch \& Boesch, 1989; Samuni et al., 2018b). Nevertheless, we can report that adult females

526 continued hunting and meat eating behaviors also during years when there were no or just one

527 adult male in the North group. The North group had no adult males for four years and only one

528 adult male for another six years, but a minimum of four adult females that continued to hunt and

529 eat meat during this period. Although hunting frequencies seemed reduced, it is impressive that

530 females engaged successfully in this behavior, further supporting the evidence that meat has a high

531 nutritional value for chimpanzees. Impressively, low-ranking females and even nursing mothers

532 joined these aggressive meat-eating events and were successful in accessing meat, which

533 strengthens further the importance of meat in the female chimpanzee diet.

535 Conclusion

536 The benefits of female dominance rank for accessing meat are positive and robust to fruit 537 abundance variations and large demographic changes (and hence some group level social changes 538 such as in dominance hierarchies). Taken together this indicates that this female social property is

539 persistent even when the competition for resources declines because of overall community size 540 declines or fruit abundance increases. Furthermore, other female properties such as age, oestrus 541 status and the nursing of a small infant positively influenced meat access.

542

\section{Acknowledgments}

544 We thank the Ministère des Eaux et Forêts, Ministère de l'Enseignement supérieur et de la

545 Recherche scientifique, and the Office Ivoirien des Parcs et Réserves for permitting this research, 546 and the Centre Suisse de Recherche Scientifique at Abidjan in Côte d'Ivoire for their logistical 
547 support; and the Max Planck Society. We thank the Taï Chimpanzee Project (TCP) and especially

548 the TCP field assistants Camille Bolé, Nicaise Oulaï, Honora Kpazahi, Grégoire Nohon and Nestor

549 Gouyan Bah, who collected the long-term data presented here. We are grateful to Roger Mundry

550 for statistical advice and Robert Power for insights into human meat eating literature. This research

551 was conducted in accordance with the animal care regulations and national laws of Côte d'Ivoire

552 and Germany. Two reviewers and Editor Dr Antje Engelhardt provided important comments on

553 an earlier version of this manuscript that substantially improved it. The viewpoints expressed are

554 those of the authors and do not necessarily reflect the opinions of the U.S. Department of the

555 Interior or the U.S. Fish and Wildlife Service.

556

\section{References}

558 Altmann J. 1974. Observational study of behavior: sampling methods. Behaviour 49:227-267.

559 Anderson DP, Nordheim EV, Boesch C, Moermond TC. 2002. Factors influencing fission-fusion

560 grouping in chimpanzees in the Taï Forest, Côte d'Ivoire. In: Boesch C, Hohmann G,

561 Marchant LF, ed. Chimpanzee behavioural diversity. Cambridge: Cambridge University

$562 \quad$ Press, 90-101.

563 Anderson DP, Nordheim EV, Moermond TC, Goné Bi ZB, Boesch C. 2005. Factors influencing

564 tree phenology in Taï National Park, Côte d'Ivoire. Biotropica 37:631-640.

565 Bates D, Maechler M, Bolker B, Walker S. 2015. Fitting Linear Mixed-Effects Models Using

566 lme4. Journal of Statistical Software 67(1): 1-48 doi:10.18637/jss.v067.i01.

567 Boesch C. 1991. The effects of leopard predation on grouping patterns in forest chimpanzees.

568 Behaviour 117:221-242. 
569 Boesch C. 2009. The Real Chimpanzee: Sex Strategies in the Forest. Cambridge: Cambridge

$570 \quad$ University Press.

571 Boesch C. 1994. Hunting strategies of Gombe and Tai Chimpanzees. In: McGrew WC, de Waal

572 FBM, Wrangham RW, Heltne P, ed. Chimpanzee Cultures. Cambridge: Harvard $573 \quad$ University Press, 77-91.

574 Boesch C, Boesch H. 1989. Hunting behavior of wild chimpanzees in the Tai National Park. American Journal of Physical Anthropology 78:547-573.

Boesch-Acherman H, Boesch C. 1994. Hominisation in the rainforest: The chimpanzee's piece to the puzzle. Evolutionary Anthropology 3(1): 9-16.

Boesch C. 1997. Evidence for dominant wild female chimpanzees investing more in sons. Animal Behaviour 54(4):811-815.

Boesch C, Boesch-Achermann H. 2000. The Chimpanzees of the Taï Forest. Behavioural Ecology and Evolution. Oxford: Oxford University Press.

Bolker BM, Brooks ME, Clark CJ, Geange SW, Poulsen JR, Stevens MHH, White JSS. 2009. Generalized linear mixed models: a practical guide for ecology and evolution. Trends in ecology \& evolution 24(3): 127-135.

Clutton-Brock TH, Harvey PH. 1978. Mammals, resources and reproductive strategies. Nature 273(5659): 191.

Deschner T, Heistermann M, Hodges K, Boesch C. 2004. Female sexual swelling size, timing of ovulation, and male behavior in wild West African chimpanzees. Hormones and Behavior 46: 204-215.

590 De Vries H. 1995. An improved test of linearity in dominance hierarchies containing unknown or tied relationships. Animal Behaviour 50(5):1375-1389. 
592 Doran D. 1997. Influence of seasonality on activity patterns, feeding behavior, ranging, and 593 grouping patterns in Taï chimpanzees. International Journal of Primatology 18:183-206.

594 Emery Thompson EM, Kahlenberg SM, Gilby IC, Wrangham RW. 2007. Core area quality is 595 associated with variance in reproductive success among female chimpanzees at Kibale 596 National Park. Animal Behaviour 73:501-512.

597 Emery Thompson EM, Muller MN, Kahlenberg SM, Wrangham RW. 2010. Dynamics of social 598 and energetic stress in wild female chimpanzees. Hormones and Behavior 58(3):440-449.

599 Emery Thompson EM, Muller MN, Wrangham RW. 2012. The energetics of lactation and the 600 return to fecundity in wild chimpanzees. Behavioral Ecology 23(6):1234-1241.

601 Faostat, F. A. O. 2014. http://www.fao.org/ag/againfo/themes/en/meat/background.html 602 Fahy GE, Richards MP, Riedel J, Hublin JJ, Boesch C. 2013. Stable isotope evidence of meat 603 eating and hunting specialization in adult male chimpanzees. Proceedings of the National Academy of Sciences of the United States of America 110(15):5829-5833.

605

606

607

608

609

610

611

612

613 614
Fawcett K. 2000. Female relationships and food availability in a forest community of chimpanzees. Thesis, University of Edinburgh.

Fox J \& Weisberg S. 2011. An R companion to Applied Regression. Second Edition. Thousand Oaks, CA: Sage. URL: http://socserv.socsci.mcmaster.ca/jfox/Books/Companion

Furuichi T. 1987. Sexual swelling, receptivity, and grouping of wild pygmy chimpanzee females at Wamba Zaire. Primates 28:309-318.

Gomes CM, Boesch C. 2009. Wild chimpanzees exchange meat for sex on a long-term basis. PLoS One 4(4): e5116.

Goodall J. 1963. Feeding behaviour of wild chimpanzees: a preliminary report. Symposium of the Zoological Society of London 10:39-48.

Peer) reviewing PDF | (2019:04:36415:1:0:NEW 28 Aug 2019) 
615 Goodall J. 1968. The behavior of free-living chimpanzees in the Gombe Stream Reserve. Animal 616 Behaviour Monographs 1:161-311.

617 Goodall J. 1986. The chimpanzees of Gombe: patterns of behavior. Cambridge: The Belknap 618 Press of Harvard University Press.

619 Gilby IC. 2006. Meat sharing among the Gombe chimpanzees: harassment and reciprocal $620 \quad$ exchange. Animal Behaviour 71(4):953-963.

621 Gilby IC, Thompson ME, Ruane JD, Wrangham R. 2010. No evidence of short-term exchange of 622 meat for sex among chimpanzees. Journal of Human Evolution 59(1):44-53.

623 Gilby IC, Machanda ZP, O'Malley RC, Murray CM, Lonsdorf EV, Walker K, Mjungu DC, Otali E, Muller MN, Thompson ME, Pusey AE, Wrangham RW. (2017). Predation by female chimpanzees: toward an understanding of sex differences in meat acquisition in the last common ancestor of Pan and Homo. Journal of human evolution, 110, 82-94.

627 Hill K. 1982. Hunting and human evolution. Journal of Human Evolution 11:521-544.

628 Hobaiter C, Samuni L, Mullins C, Akankwasa WJ, Zuberbühler K. 2017. Variation in hunting 629 behaviour in neighbouring chimpanzee communities in the Budongo forest, Uganda. PloS one 12(6), e0178065.

631 Isaac G. 1978. The food-sharing behavior of protohuman hominids. Scientific American 238: 90632 108.

Jaeggi AV, Gurven M. 2013. Natural Cooperators: Food Sharing in Humans and Other Primates. Evolutionary Anthropology 22:186-95.

Kahlenberg SM, Emery Thompson EM, Wrangham RW. 2008. Female competition over core areas in Pan troglodytes schweinfurthii, Kibale National Park, Uganda. International Journal of Primatology 29:931-947. 
638 Leakey RE. 1981. The Making of Mankind. London: Michael Joseph.

639 Lehmann J, Boesch C. 2008. Sexual differences in chimpanzee sociality. International Journal $640 \quad$ of Primatology 29:65-81.

641 Luncz LV, Mundry R, Boesch C. 2012. Evidence for Cultural Differences between Neighboring 642 Chimpanzee Communities. Current Biology 22(10):922-926

$643 \quad$ doi:10.1016/j.cub.2012.03.031.

644 McGrew WC. 1992. Chimpanzee Material Culture: Implications for Human Evolution.

645 Cambridge University Press: Cambridge.

646 Mielke A, Crockford C, Wittig RM. (in press). Rank changes in female chimpanzees in Tai

647 National Park. In: Boesch C, Wittig RM. ed. The Tai Chimpanzees: 40 years of Research.

$648 \quad$ Cambridge University Press.

649 Milton K. 1999. A hypothesis to explain the role of meat-eating in human evolution.

650 Evolutionary Anthropology: Issues, News, and Reviews 8.1:11-21.

651 Milton K. 2003. Micronutrient intakes of wild primates: are humans different. Comparative 652 Biochemistry and Physiology Part A 136: 47-59.

653 Mitani JC, Watts DP. 1999. Demographic influences on the hunting behavior of chimpanzees. 654 American Journal of Physical Anthropology 109: 439.454.

655 Mitani JC, Watts DP. 2001. Why do chimpanzees hunt and share meat? Animal Behavior 61: $6569915-924$.

657 Mitani JC, Watts DP, Lwanga JS. 2002. Ecological and social correlates of chimpanzee party 658 size and composition. In: Boesch C, Hohmann G, Marchant L, ed. Behavioural diversity 659 in chimpanzees and Bonobos. Cambridge University Press. 
660 Morgan D, Sanz C. 2006. Chimpanzee feeding ecology and comparisons with sympatric gorillas 661 in the Goualougo Triangle, Republic of Congo. In: Hohmann G, Robbins MM, Boesch C, 662 ed. Feeding ecology in apes and other primates: Ecological, physical and behavioral 663 aspects. Cambridge: Cambridge University Press, 97-122.

664 Muller MN, Emery Thompson ME, Wrangham RW. 2006. Male chimpanzees prefer mating with $665 \quad$ old females. Current Biology 16(22):2234-2238.

666 Murray CM, Eberly LE, Pusey AE. 2006. Foraging strategies as a function of season and rank 667 among wild female chimpanzees. Behavioral Ecology 17:1020-1028.

668 Murray CM, Mane SV, Pusey AE. 2007. Dominance rank influences female space use in wild 669 chimpanzees, Pan troglodytes: towards an ideal despotic distribution. Animal Behaviour 670 $74: 1795-1804$.

671 Nishida T. 1989. Social interactions between resident and immigrant female chimpanzees. In: Heltne P, Marquardt L, ed. Understanding chimpanzees. Cambridge: Harvard University Press, Mass, 68-89.

674 Nishida T. 1990. The chimpanzees of the Mahale Mountains. Tokyo: Tokyo University Press.

675 O'Malley RC, Stanton MA, Gilby IC, Lonsdorf EV, Pusey A, Markham AC, Murray CM. 2016.

676 Reproductive state and rank influence patterns of meat consumption in wild female chimpanzees (Pan troglodytes schweinfurthii). Journal of Human Evolution 90:16-28.

678 Otali E, Gilchrist JS. 2006. Why chimpanzee (Pan troglodytes schweinfurthii) mothers are less 679 680 gregarious than nonmothers and males: the infant safety hypothesis. Behavioral Ecology and Sociobiology 59:561-570.

681 Polansky L, Boesch C. 2013. Long-term changes in fruit phenology in a West African lowland 682 tropical rain forest are not explained by rainfall. Biotropica 45(4):434-440. 
683 Pruetz JD. 2006. Feeding ecology of chimpanzees in a savanna environment. In: Boesch C,

684 Robbins M, eds. The feeding ecology of apes and other primates. pp. 161-182.

685 Cambridge, UK: Cambridge University Press.

686 Pruetz JD, Bertolani P, Ontl KB, Lindshield S, Shelley M, Wessling EG. 2015. New evidence on 687 the tool-assisted hunting exhibited by chimpanzees (Pan troglodytes verus) in a savannah 688 habitat at Fongoli, Sénégal. Royal Society Open Science 2(4):140507.

Pusey AE, Williams JM, Goodall J. 1997. The influence of dominance rank on the reproductive 690 success of female chimpanzees. Science 277:828-831.

691

692

693

694

695

696

697

698

699

700

701

702

703

704 705

Pusey AE, Oehlert GW, Williams JM, Goodall J. 2005. Influence of Ecological and Social Factors on Body Mass of Wild Chimpanzees. International Journal of Primatology 26:331.

R Core Team. 2018. R: A language and environment for statistical computing. R Foundation for Statistical Computing, Vienna, Austria. URL https://www.R-project.org/.

Riedel J, Franz M, Boesch C. 2011. How feeding competition determines female chimpanzee gregariousness and ranging in the Taï National Park, Côte d'Ivoire. International Journal of Primatology 73:305-313.

Sakura O. 1994. Factors affecting party size and composition of chimpanzees (Pan troglodytes verus) at Bossou, Guinea. International Journal of Primatology 15:167-183.

Samuni L, Preis A, Mielke A, Deschner T, Wittig RM, Crockford C. 2018a. Social bonds facilitate cooperative resource sharing in wild chimpanzees. Proceedings of the Royal Society London B 285(1888):20181643.

Samuni L, Preis A, Deschner T, Crockford C, Wittig R. 2018b. Reward of labor coordination and hunting success in wild chimpanzees. Communications Biology 1:138. 
706 Stanford CB. 1999. The hunting apes: meat eating and the origins of human behavior. Princeton,

707 NJ: Princeton University Press.

708 Sugiyama Y, Koman J. 1992. The flora of Bossou: its utilization by chimpanzees and humans.

709 African Study Monographs 13:127-169.Takahata Y. 1990. Adult males' social relations

710 with adult females. In: Nishida T, ed. The Chimpanzees of the Mahale Mountains. Tokyo:

$711 \quad$ University of Tokyo Press, $133-148$.

712 Tennie C, Gilby IC, Mundry R. 2009. The meat-scrap hypothesis: small quantities of meat may

713 promote cooperative hunting in wild chimpanzees (Pan troglodytes). Behavioral Ecology

714 and Sociobiology 63: 421-431.

715 Uehara S, Nishida T, Hamai M, Hasegawa T, Hayaki H, Huffman M, Kawanaka K, Kobayoshi

716 S, Mitani J, Takahata Y, Takasaki H, Tsukahara T. 1992. Characteristics of predation by

717 the chimpanzees in the Mahale Mountains National Park, Tanzania. In: Nishida T,

718 McGrew WC, Marler P, Pickford M, de Waal FBM, ed. Topics in Primatology, Volume

719 1: Human Origins. Tokyo: University of Tokyo Press, 143-158.

720 Wakefield M. 2002. Female chimpanzee allogrooming behavior at Ngogo, Kibale National Park,

721 Uganda. American Journal of Physical Anthropology 34:160-161.

722 Washburn SL. 1978. The evolution of Man. Scientific American 239:194-208.

723 Washburn SL, Lancaster CS. 1968. The evolution of hunting. In: Lee RB, DeVore I, ed. Man the 724 Hunter. Aldine: New York, 293-303.

725 Watts DP, Mitani JC. 2002. Hunting behavior of chimpanzees at Ngogo, Kibale National Park, $726 \quad$ Uganda. International Journal of Primatology 23. 
727 Williams JM, Pusey AE, Carlis JV, Farms BP, Goodall J. 2002a. Female competition and male

728 territorial behaviour influence female chimpanzees' ranging patterns. Animal Behaviour $729 \quad 63: 347-360$.

730 Williams JM, Liu H, Pusey AE. 2002b. Costs and benefits of grouping for female chimpanzees 731 at Gombe. In: Boesch C, Hohmann G, Marchant L. ed. Behavioural Diversity in 732 Chimpanzees and Bonobos. Cambridge: Cambridge University Press, 192-203.

733 Wittig RM, Boesch C. 2003. Food competition and linear dominance hierarchy among female chimpanzees of the Taï National Park. International Journal of Primatology 24:847-867.

735

736

737

738

739

740

741

742

743

744 745

746

747

Wrangham RW. 1975. The behavioural ecology of chimpanzees in the Gombe Stream National Park. Ph.D. thesis. University of Cambridge, Cambridge.

Wrangham RW. 1987. The significance of African apes for reconstructing human social evolution. The evolution of human behavior: Primate models 51-71.Wrangham RW. 2000. Why are male chimpanzees more gregarious than mothers? A scramble competition hypothesis. In: Kappeler PM, ed. Male primates. Cambridge: Cambridge University Press, 248-258.

Wrangham RW, Smuts BB. 1980. Sex differences in the behavioural ecology of chimpanzees in the Gombe National Park, Tanzania. Journal of Reproduction and Fertility 28: 13-31.

Wrangham RW, Clark AP, Isabirye-Basuta G. 1992. Female social relationships and social organization of the Kibale Forest chimpanzees. In: Nishida T, McGrew WC, Marler P, Pickford M, de Waal FDM, ed. Topics in primatology. Tokyo: University of Tokio Press, $81-98$. 
748 Wrangham RW, Conklin-Brittain NL, Hunt KD. 1998. Dietary response of chimpanzees and cercopithecines to seasonal variation in fruit abundance: I. Antifeedants. International Journal of Primatology 19:949-970.

751 Zuur AF, Ieno EN, Walker NJ, Saveliev AA, Smith GM. 2009. Mixed effects models and extensions in ecology with R. Springer: New York. 


\section{Figure 1}

Figure 1: Yearly maximal community size during the study period for North group (grey line) from 1987 until 2014 and for South group (black line) from 1999 until 2014.

Figure 1: Yearly maximal community size during the study period for North group (grey line) from 1987 until 2014 and for South group (black line) from 1999 until 2014. 


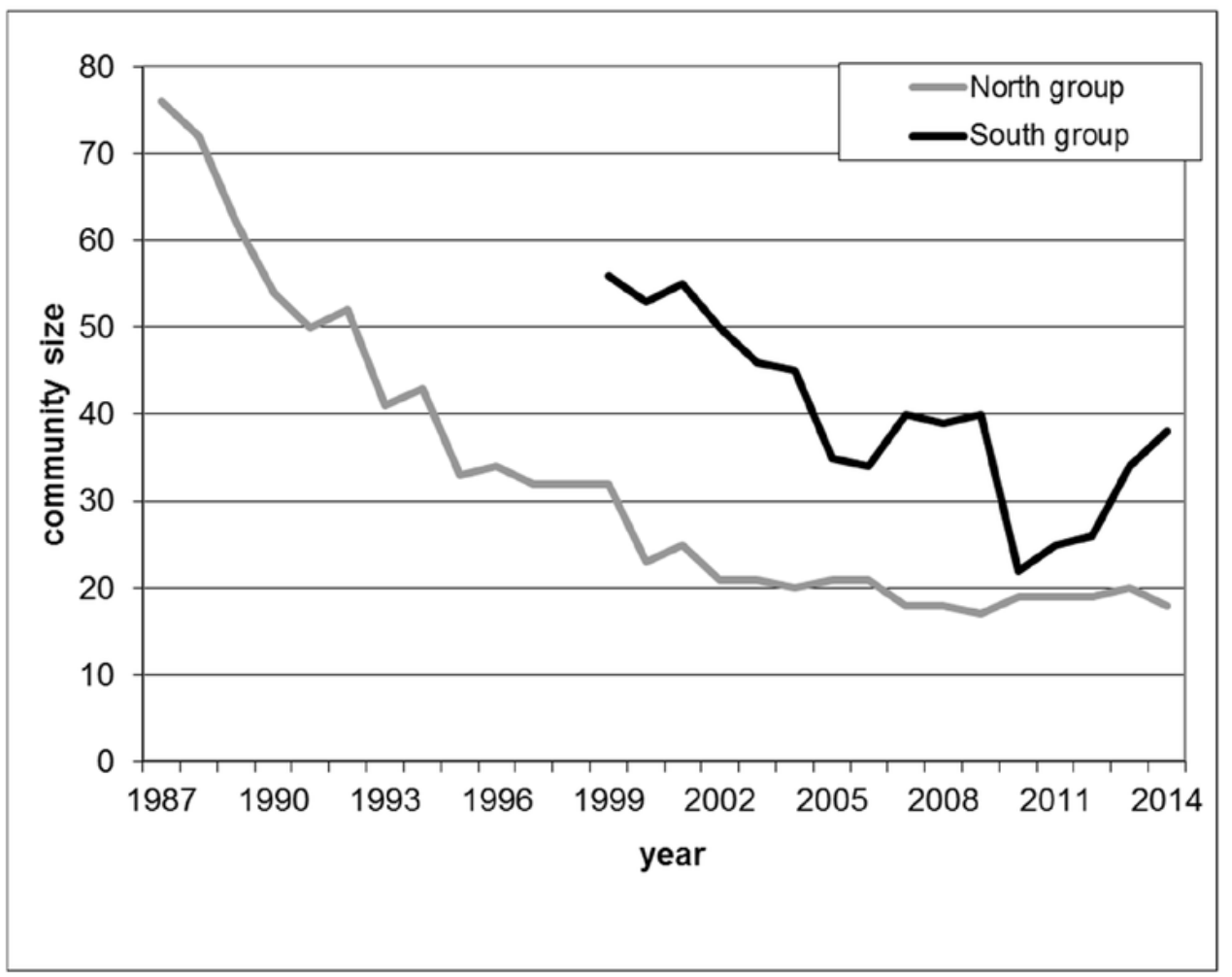


Figure 2

Figure 2: Monthly variation in the meat eating frequency controlled for the total observation time and monthly fruit abundance index (FAl).

Figure 2: Monthly variation in the meat eating frequency controlled for the total observation time (min) for North and South group with a peak in September and October. Second Y-Axis shows the monthly fruit abundance index (FAI) with an increase in FAl during the two meat eating peak months. 


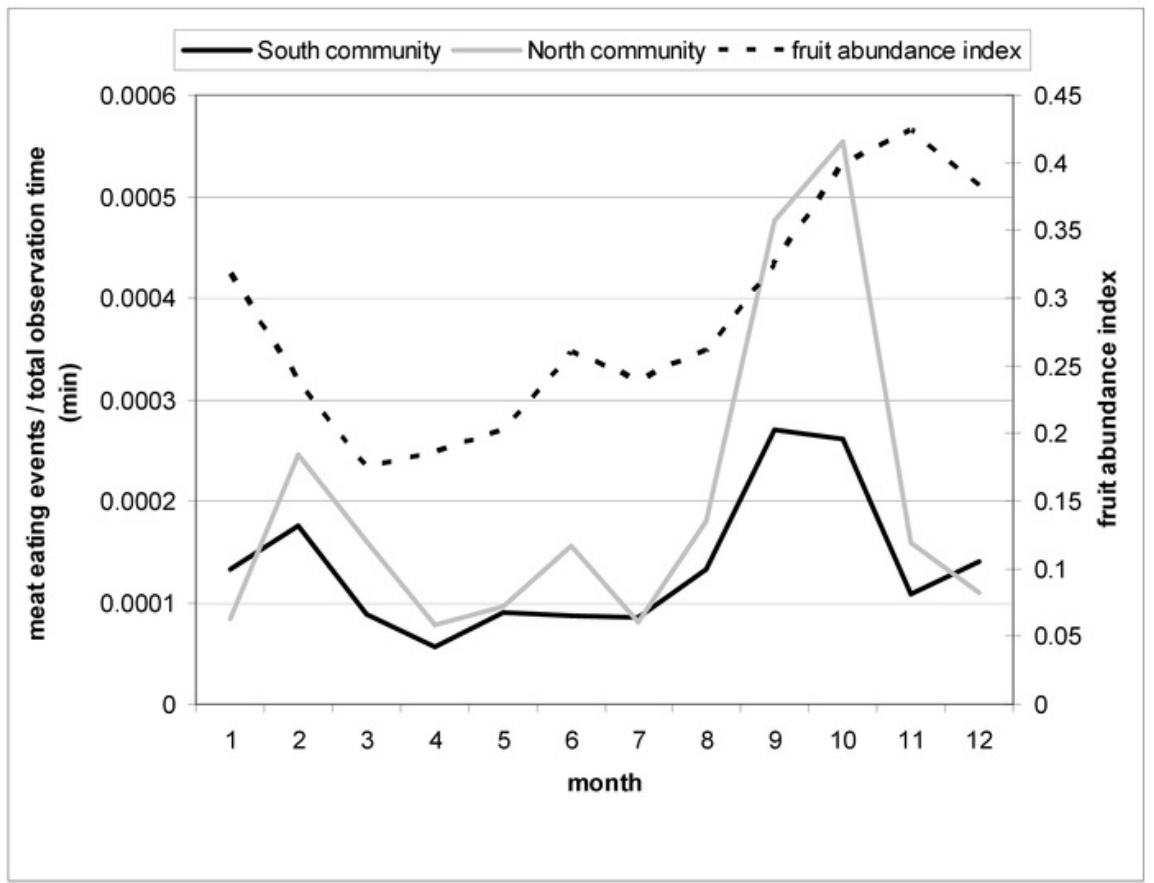




\section{Table $\mathbf{1}$ (on next page)}

Table 1: Summary of models for the probability of being present at meat eating events.

Table 1: Summary of models for the probability of being present at meat eating events. The term estimates columns show the estimate (Est), standard error (SE), and Z-value for model parameters, where the entries along the rows that do not include interactions (denoted by a colon) are based on the fitted reduced model with no interactions and the entries for rows with interactions are based on the fitted full model with all interactions and main effects. The term significance entries show results of likelihood ratio tests between either the full (when testing the importance of an interaction) or reduced model (when testing the importance of a predictor variable in isolation) and a model with the corresponding term removed; $\chi^{2}$ - test statistic; df- degrees of freedom. Significant model parameters are marked bold. 
1 Table 1: Summary of models for the probability of being present at meat eating events. The term 2 estimates columns show the estimate (Est), standard error (SE), and Z-value for model 3 parameters, where the entries along the rows that do not include interactions (denoted by a colon) 4 are based on the fitted reduced model with no interactions and the entries for rows with 5 interactions are based on the fitted full model with all interactions and main effects. The term 6 significance entries show results of likelihood ratio tests between either the full (when testing the 7 importance of an interaction) or reduced model (when testing the importance of a predictor 8 variable in isolation) and a model with the corresponding term removed; $\chi^{2}$ - test statistic; df9 degrees of freedom. Significant model parameters are marked bold.

\begin{tabular}{|l|c|c|r|r|r|r|}
\hline & \multicolumn{3}{|c|}{ Term estimates } & \multicolumn{3}{c|}{ Term significance } \\
\hline Terms & \multicolumn{1}{|c|}{ Est } & \multicolumn{1}{c|}{ SE } & Z-value & $\chi^{2}$ & df & P-value \\
\hline Intercept & -1.080 & 0.222 & -4.871 & - & - & - \\
\hline $\begin{array}{l}\text { Dominance rank (high- } \\
\text { middle) }\end{array}$ & $\mathbf{1 . 0 8 6}$ & $\mathbf{0 . 1 9 9}$ & $\mathbf{5 . 4 4 9}$ & $\mathbf{3 2 . 2 5 5}$ & $\mathbf{2}$ & $<\mathbf{0 . 0 0 1}$ \\
\hline Dominance rank (middle-low) & 0.425 & 0.163 & 2.613 & - & - & - \\
\hline Age & 0.194 & 0.112 & 1.736 & 2.735 & 1 & 0.098 \\
\hline Nursing a small infant (yes) & $\mathbf{0 . 2 4 3}$ & $\mathbf{0 . 0 7 5}$ & $\mathbf{3 . 2 5 0}$ & $\mathbf{1 0 . 3 1 2}$ & $\mathbf{1}$ & $\mathbf{0 . 0 0 1}$ \\
\hline Oestrous status (yes) & $\mathbf{1 . 2 3 4}$ & $\mathbf{0 . 1 0 2}$ & $\mathbf{1 2 . 0 9 7}$ & $\mathbf{1 5 0 . 8 4 2}$ & $\mathbf{1}$ & $<\mathbf{0 . 0 0 1}$ \\
\hline Fruit Abundance Index (FAI) & $\mathbf{0 . 1 5 7}$ & $\mathbf{0 . 0 6 2}$ & $\mathbf{2 . 5 3 9}$ & $\mathbf{6 . 3 2 5}$ & $\mathbf{1}$ & $\mathbf{0 . 0 1 2}$ \\
\hline Number of males & $\mathbf{- 0 . 3 4 0}$ & $\mathbf{0 . 0 9 9}$ & $\mathbf{- 3 . 4 4 4}$ & $\mathbf{1 1 . 2 7 5}$ & $\mathbf{1}$ & $\mathbf{0 . 0 0 1}$ \\
\hline Number of females & -0.181 & 0.103 & -1.760 & 2.915 & 1 & 0.088 \\
\hline Community ID (South) & -0.190 & 0.273 & -0.694 & 0.481 & 1 & 0.488 \\
\hline $\begin{array}{l}\text { Dominance rank (high-middle) : } \\
\text { No. of females }\end{array}$ & -0.240 & 0.156 & -1.533 & 4.342 & 2 & 0.114 \\
\hline $\begin{array}{l}\text { Dominance rank (middle-low) : } \\
\text { No. of females }\end{array}$ & -0.288 & 0.138 & -2.095 & & - & - \\
\hline $\begin{array}{l}\text { Dominance rank (high-middle) : } \\
\text { FAI }\end{array}$ & 0.088 & 0.082 & 1.079 & 1.971 & 2 & 0.373 \\
\hline $\begin{array}{l}\text { Dominance rank (middle-low) : } \\
\text { FAI }\end{array}$ & 0.116 & 0.082 & 1.412 & & - & - \\
\hline $\begin{array}{l}\text { Dominance rank (high-middle) : } \\
\text { Community ID (South) }\end{array}$ & 0.069 & 0.436 & 0.159 & 1.898 & 2 & 0.387 \\
\hline $\begin{array}{l}\text { Dominance rank (middle-low) : } \\
\text { Community ID (South) }\end{array}$ & 0.459 & 0.399 & 1.149 & & & - \\
\hline $\begin{array}{l}\text { Dominance rank (high-middle) : } \\
\text { Oestrous status (yes) }\end{array}$ & 0.199 & 0.260 & 0.764 & 0.998 & 2 & 0.607 \\
\hline $\begin{array}{l}\text { Dominance rank (middle-low) : } \\
\text { Oestrous status (yes) }\end{array}$ & -0.044 & 0.236 & -0.186 & & - & - \\
\hline
\end{tabular}




\section{Table 2 (on next page)}

Table 2: Summary of models of the probability of meat access given presence at an event.

Table 2: Summary of models of the probability of meat access given presence at an event. See the caption for Table 1 for details on entries. 
1 Table 2: Summary of models of the probability of meat access given presence at an event. See

2 the caption for Table 1 for details on entries.

\begin{tabular}{|c|c|c|c|c|c|c|}
\hline & \multicolumn{3}{|c|}{ Term estimates } & \multicolumn{3}{|c|}{ Term significance } \\
\hline Terms & Est & $\mathrm{SE}$ & Z-value & $\chi^{2}$ & $\mathrm{df}$ & P-value \\
\hline Intercept & -0.080 & 0.212 & -0.376 & - & - & - \\
\hline $\begin{array}{l}\text { Dominance rank (high - } \\
\text { middle) }\end{array}$ & 1.090 & 0.208 & 5.232 & 26.206 & 2 & $<0.001$ \\
\hline Dominance rank (middle - low) & 0.707 & 0.171 & 4.138 & - & - & - \\
\hline Age & 0.402 & 0.094 & 4.286 & 18.708 & 1 & $<0.001$ \\
\hline Nursing a small infant (yes) & 0.293 & 0.083 & 3.514 & 11.999 & 1 & 0.001 \\
\hline Oestrous status (yes) & 0.459 & 0.138 & 3.335 & 10.9 & 1 & 0.001 \\
\hline Fruit Abundance Index (FAI) & 0.091 & 0.070 & 1.300 & 1.655 & 1 & 0.198 \\
\hline Number of males & -0.046 & 0.090 & -0.507 & 0.259 & 1 & 0.611 \\
\hline Number of females & -0.321 & 0.077 & -4.184 & $\mathbf{1 7 . 5 7}$ & 1 & $<0.001$ \\
\hline Community size & -0.193 & 0.095 & -2.030 & 4.001 & 1 & 0.045 \\
\hline Community ID (South) & -0.068 & 0.231 & -0.295 & -0.043 & 1 & 1 \\
\hline $\begin{array}{l}\text { Dominance rank (high-middle) } \\
\text { : No. of females }\end{array}$ & 0.080 & 0.114 & 0.698 & 1.804 & 2 & 0.406 \\
\hline $\begin{array}{l}\text { Dominance rank (middle-low) } \\
\text { : No. of females }\end{array}$ & 0.149 & 0.113 & 1.321 & - & - & - \\
\hline $\begin{array}{l}\text { Dominance rank (high-middle) } \\
\text { : FAI }\end{array}$ & 0.160 & 0.109 & 1.465 & 2.385 & 2 & 0.303 \\
\hline $\begin{array}{l}\text { Dominance rank (middle-low) } \\
\text { : FAI }\end{array}$ & 0.144 & 0.109 & 1.327 & - & - & - \\
\hline $\begin{array}{l}\text { Dominance rank (high-middle) } \\
\text { : Community ID (South) }\end{array}$ & -0.200 & 0.393 & -0.511 & 0.45 & 2 & 0.798 \\
\hline $\begin{array}{l}\text { Dominance rank (middle-low) } \\
\text { : Community ID (South) }\end{array}$ & 0.027 & 0.339 & 0.078 & - & - & - \\
\hline $\begin{array}{l}\text { Dominance rank (high-middle) } \\
\text { : Oestrous status (yes) }\end{array}$ & 0.585 & 0.353 & 1.658 & 2.87 & 2 & 0.238 \\
\hline $\begin{array}{l}\text { Dominance rank (middle-low) } \\
\text { : Oestrous status (yes) }\end{array}$ & 0.399 & 0.341 & 1.170 & - & - & - \\
\hline
\end{tabular}

